\title{
A global genetic epidemiological review of pseudoexfoliation syndrome
}

Patrice M. Hicks ${ }^{1,2}\left(\mathbb{0}\right.$, Adam Siedlecki ${ }^{3}$, Benjamin Haaland ${ }^{1}$, Leah A. Owen ${ }^{1,2,3}\left(\mathbb{D}\right.$, Elizabeth $\mathrm{Au}^{3}$, Michael

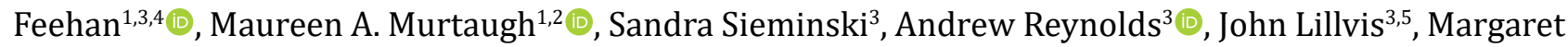
M. DeAngelis $\mathbf{s}^{1,2,3,5 *(1)}$

\section{${ }^{1}$ Department of Population Health Sciences, University of Utah School of Medicine, Salt Lake City, UT 84108, USA \\ ${ }^{2}$ Department of Ophthalmology and Visual Sciences, University of Utah School of Medicine, Salt Lake City, UT 84132, USA \\ ${ }^{3}$ Department of Ophthalmology, Jacobs School of Medicine and Biomedical Engineering, SUNY-University at Buffalo, Buffalo, NY 14209, USA \\ ${ }^{4}$ Cerner Enviza, Kansas City, MO 64117, USA \\ ${ }^{5}$ VA Western New York Healthcare System, Buffalo, NY 14215, USA}

*Correspondence: Margaret M. DeAngelis, Department of Ophthalmology, Jacobs School of Medicine and Biomedical Engineering, SUNY-University at Buffalo, 1176 Main St, Buffalo, NY 14209, USA. mmdeange@buffalo.edu

Academic Editor: Derek M. Dykxhoorn, University of Miami Miller School of Medicine, USA

Received: June 11, 2021 Accepted: August 25, 2021 Published: December 31, 2021

Cite this article: Hicks PM, Siedlecki A, Haaland B, Owen LA, Au E, Feehan M, et al. A global genetic epidemiological review of pseudoexfoliation syndrome. Explor Med. 2021;2:527-43. https://doi.org/10.37349/emed.2021.00069

\begin{abstract}
Pseudoexfoliation (PXF) syndrome is an important public health concern requiring individual population level analysis. Disease prevalence differs by geographic location and ethnicity, and has environmental, demographic, genetic, and molecular risk factors have been demonstrated. Epidemiological factors that have been associated with PXF include age, sex, environmental factors, and diet. Genetic and molecular components have also been identified that are associated with PXF. Underserved populations are often understudied within scientific research, including research about eye disease such as PXF, contributing to the persistence of health disparities within these populations. In each population, PXF needs may be different, and by having research that identifies individual population needs about PXF, the resources in that population can be more efficiently utilized. Otherwise, PXF intervention and care management based only on the broadest level of understanding may continue to exacerbate health disparities in populations disproportionally burdened by PXF.
\end{abstract}

\section{Keywords}

Global, genetic, epidemiological, review, pseudoexfoliation

\section{Introduction}

Pseudoexfoliation (PXF) syndrome, first described by Lindberg [1-3] in 1917, is a systemic disease. It causes various tissues, including the tissues in the eye, to accumulate gray and white material. The etiology of PXF is still unknown. Over 100 years later, it still represents a significant clinical problem. The disease affects more than 60 to 70 million people globally [3-10]. PXF pathophysiology is characterized by systemic deposition 
of fibrillary material [11-13]. Ocular deposition occurring in the trabecular meshwork [6, 14], cornea, lens, and pupillary iris border leads to significant ocular and visual morbidity. This can include cataract formation, and zonular weakness, leading to lenticular dislocation and glaucoma $[6,15,16]$. Other conditions including coronary artery disease, hypertension (HTN), dementia, and sensory hearing loss have also been correlated with PXF pathogenesis due to abnormalities in the breakdown, production, and extracellular deposit of fibrillary material in the visceral organs and blood vessels [17-19]. While the full spectrum of pathogenesis resulting from fibrillary deposition is unknown, it has been speculated that oxidative stress, elastosis, endothelial dysfunction, and weakened autonomic regulation result from its accumulation [20]. This is evidenced by the finding that PXF syndrome is an independent risk factor for coronary artery disease. Specifically, significant correlations were found between PXF and cardiovascular disease outcomes (ischemic heart disease, cardiomyopathy, and aortic aneurysm) in a case-control study of 6,046 cases of PXF in the Veteran's Health Administration databases [21]. PXF confers significant morbidity and mortality, and there remains no cure. Treatment is directed at the resultant pathobiology and includes systemic medications and ocular laser or incisional intervention $[6,18,22]$. Thus, PXF is an important public health concern requiring individual population level analysis. Disease prevalence differs by geographic location and ethnicity, and environmental, demographic, genetic, and molecular risk factors have been identified [23-25].

\section{Ophthalmic effects of PXF}

PXF ocular manifestations are directly evident through visualization of fibrillary material deposition using slit lamp biomicroscopy. PXF can be seen unilaterally or bilaterally. Unilateral cases may become bilateral over time, as this is a systemic disease that increases in severity with age [26-29]. Whether unilateral or bilateral, PXF has significant ocular morbidities, all of which can result in significant visual impairment or blindness. This highlights the importance of investigation to better understand the etiology of PXF with a goal of identifying curative, rather than temporizing, treatments [30-32].

\section{Glaucoma}

Glaucoma is a leading cause of blindness globally and results in progressive visual field loss due to optic nerve damage [33-38]. Glaucoma often occurs in the setting of elevated intraocular pressure (IOP). Globally, PXF is the leading cause of the open-angle glaucoma, accounting for up to $25 \%$ of all glaucoma cases $[28,39,40]$. Conversely, 15 to 30 percent of those diagnosed with PXF will subsequently develop PXF glaucoma (PXG) [6]. PXG demonstrates increased severity compared with other forms of primary open-angle glaucoma (POAG). In PXG, increased IOP results from the deposition of fibrillary material in the trabecular meshwork, the drain of the eye. This unique characteristic results in PXF specific ocular morbidity. IOP is often more significantly elevated in PXG, resulting in a greater degree of visual field loss. There is also a blunted treatment response in PXG patients compared to POAG patients [41-43]. Therefore, PXG patients who do not seek care for their glaucoma or are not adherent to medical treatment can more often suffer irreversible blindness [41-46]. Ocular manifestations of PXG have been linked to both epidemiological and genetic risk factors $[23,47,48]$. The prevalence of PXG and its risk factors have been found to differ by geographic location and a person's ethnicity [41]. Improved identification of risk factors associated with individual populations to best identify screening implications for PXF around the globe will aid in the prevention of PXG-associated blindness.

\section{Cataract}

Cataract is the leading cause of preventable blindness and vision loss, accounting for $51 \%$ of global blindness [49]. Cataract is present when the natural lens becomes opaque and can result in low night vision, decreased vision, blindness, double vision, and decreased contrast sensitivity [50-53]. Most cataracts involve central, nuclear lenticular changes and are age-associated [50, 54]. Cataract blindness disproportionately affects low-resource areas worldwide due to limited access to preventative eye care services [55-58]. PXF is associated with an increased risk of nuclear cataract [59-61]. The molecular pathobiology underlying this clinical finding is unknown, but the preponderance of data suggests this 
is due to oxidative stress $[59,60,62]$. Importantly, PXF not only increases risk for cataract, due to zonular fibrillary deposition and resultant weakness, cataract surgery can be more complex in the presence of PXF and often results in surgical complications. These surgical challenges include poor pupillary dilation, postoperative IOP increase, capsular bag dislocation, and prolonged postoperative inflammation [8]. Therefore, the presence of PXF is an important clinical determinant of the degree of successful treatment of cataract-associated vision loss, and those with PXF should be counseled on the potential complications associated with cataract surgery. Further investigation into the molecular etiology and natural history of PXF is necessary to minimize the primary and secondary sequela of cataract blindness in these patients.

\section{Other ocular manifestations}

Other less well-characterized ocular manifestations of PXF include lens dislocation and dry eye syndrome. As a result of ocular surface and eyelid fibrillary deposition, tear production and osmolarity are altered, resulting in decreased tear break up time, poor tear quality, and dry ocular surface [63-65]. Individuals with PXF are therefore at a higher risk for developing dry eye disease $[63,66,67]$. Lens dislocation may occur in individuals with PXF after cataract surgery $[27,68,69]$. Additionally, research has shown that individuals with PXF are at a higher risk of developing intraocular lens dislocations than individuals having cataract surgery without PXF $[68,69]$.

\section{Epidemiological risk of PXF}

Age

PXF is an age-related disease as its risk increases with age [70-72]. Clinical evidence of PXF is uncommon under 40 to 50 years of age. To date, only 12 cases of PXF have been identified in those aged less than 40 years [9, 73]. In contrast, PXF can affect up to $25 \%$ of individuals aged $60+$ years old [73]. PXF is associated with other diseases of aging, and it remains unclear if this is due to aging as a standard risk variable or shared pathogenesis. For example, among 777 Greek individuals aged 40-99 years, those with PXF were more likely to have age-related macular degeneration [74]. Additional investigation is needed to clarify the role of aging in this association. Indeed, the clinical importance of aging diseases will increase going forward as the number of individuals aged $60+$ years old is projected to increase 12 to $22 \%$ globally between the years 2015 to $2055[75,76]$. Moreover, the aging population is becoming more ethnically and racially diverse, including more non-Hispanic whites within the elderly population [77-80]. As PXF risk factors and prevalence differ by ethnicity and geographic location, it will be essential to identify how these differences may impact the prevention and management of secondary outcomes such as ocular manifestations and systemic disease with PXF [24, 25].

\section{Sex}

As is the case with other medical conditions, including osteoarthritis, stroke, and lupus, women experience PXF at higher rates than men [81-83]. This may because in most places around the globe, women live longer than men, and age is a risk factor for PXF [84-86]. Additionally, women in low-resource countries/ regions have poorer detection and prevention of PXF due to less access to general preventative and medical care [87]. Over and above age and health care access discrepancies, it appears women may have different social and biological risk factors for the disease compared to men [88]. Understanding biologic determinants of PXF disease that exacerbate the risk for women is vital across geographies and populations. It is essential to include women from different ethnicities and cultures within clinical research, as advancements from this research can help to benefit the health and healthcare of women around the globe [81, 88-91].

\section{Environmental factors}

PXF has been linked to certain environmental factors that increase the likelihood of developing or hastens its development. Research focused on the potential association between geographic location and PXF has found that elevation may increase the risk for PXF [74, 92]. In Greece, those living in higher altitudes had 
a higher prevalence of PXF than those at lower elevations [74]. Time spent outdoors and solar exposure are also associated with PXF risk [92-95]. In a retrospective observational study conducted with 626,901 participants in the US, PXF was positively associated with altitude, more time spent outdoors, and increased sunlight exposure. A cross-sectional study conducted in Andhra Pradesh examined 10,293 participants of all ages and found that those who had occupations that required them to work outdoors had higher rates of PXF [95]. Another study of 49,033 women and 20,066 men aged 60+ years old found that people who spend more time outdoors in youth (i.e., high school to 24 years old) had a higher risk for PXG or being considered a PXG suspect [94]. A clinic-based case-control study in US and Israeli populations investigated solar exposure and development of PXF [93]. The study, which included 185 cases and 178 controls, found that cases of PXF were more likely to be seen in those who were older, had lighter colored eyes, and had a family history of glaucoma [93]. Therefore, those in public health should consider individuals who live in areas of high altitude or those who have greater sunlight exposure to be more closely followed for early detection of PXF. Increased awareness should also be brought to these populations at a higher risk for PXF as some of these risk factors are modifiable and thus preventable.

\section{Diet}

Diet has been linked to PXF [73, 96-98]. A cross-sectional study in East India with 346 participants found that those who had PXF were more likely to be non-vegetarians and primarily consume fish [96]. This study also found that individuals that consumed a higher amount of coffee (more than 3 cups per day) had a higher likelihood of developing PXF and PXG [96]. Similarly, higher coffee consumption, was associated with PXF and PXG in a cohort study of 78,977 women and 41,202 men [97]. The association was higher in women who had a family history of glaucoma [97]. Vitamin deficiency has also been associated with PXF and PXG [98]. A prospective cohort study, including men and women, found that higher folate intake was associated with a lower risk for developing PXG or becoming a PXG suspect [98]. Diet is another modifiable risk factor that those in public health may address within populations at a higher risk for developing PXF.

\section{Genetic risk}

\section{LOXL1}

LOXL1, a gene for a lysyl oxidase, is the principal genetic contributor to PXF with a well-established association [99-102]. Specifically, three single nucleotide polymorphisms (SNPs) of interest have been associated with PXF and PXG [99-102]. Two of these SNPs, rs1048661, and rs3825942, are missense variants located in exon one and yield the G allele associated with PXF $[103,104]$. The third SNP, rs2165241, is located in intron $1[103,104]$. These LOXL1 SNPs and their association with PXF have been confirmed in varied populations around the world, including Europe [99, 103, 105], North America [104, 106-109], Asia [100, 110-112], Africa [113, 114], and Australia [115]. Though the association between LOXL1 and PXF has been demonstrated in many populations, the association between the G allele and PXF was not the same in every case. In a matched, hospital-based case-control study in South Africa, an association was found with LOXL1. However, the associated G allele with SNP rs3825942 was found to have a decreased risk for PXF [114]. In some instances, LOXL1 may not be associated with PXF. In a North Indian population, a case-control study conducted with 118 study participants found a lack of association between LOXL1 and PXF [116]. A candidate gene approach may be implemented to determine if LOXL1 is associated with these other populations. Notably, LOXL1 has not been researched explicitly in South American populations but has been confirmed within a Latin American population from Mexico City [109]. There has been one case report from Brazil that has confirmed the association of LOXL1 and PXF [117]. Further research is needed to confirm that the genetic association is manifested within individual populations that have not yet been studied.

\section{CACNA1A}

CACNA1A, a gene encoding a voltage-gated calcium channel subunit, has been established as a genetic contributor to PXF [118-120]. The CACNA1A SNP rs492644 had genome-wide significance for association 
with increased risk for developing PXF [118-122]. Similar to LOXL1, the G allele was associated with a higher risk for PXF. A genome-wide association study was conducted with 1,188 controls and 1,484 cases within a Japanese population [119]. The genome-wide association study (GWAS) study, which included 13,838 cases and 110,275 controls, validated this finding in 17 other countries, including Argentina, Poland, Greece, Turkey, China, Iran, India, and South Africa $[119,120]$. Further research could be conducted in other countries not already included among the 17 used in the GWAS study to confirm CACNA1A SNP rs492644 with PXF in all populations. Similar to the LOX1 associated findings, there may be studies that find that CACNA1A decreases the risk of PXF, or has no association with PXF in specific populations. Further research in understudied populations may determine if the GWAS findings hold.

\section{Additional identified genes}

GWAS have identified five additional genes, including SEMA6A, AGPAT1, FLT1-POMP, TMEM136-ARHGEF12, and RBMS3 [120]. Some genes have been identified in specific populations, but further research is needed within a multiethnic study to determine if these genes remain associated with other populations around the globe. For example, TBC1D21 is associated with PXF within a Japanese and Uyghur Asian population $[123,124]$. The study conducted within the Japanese population used a genome-wide association study, while the Uyghur population study utilized a candidate gene approach [122, 123]. A candidate gene approach could be conducted to determine if these genes remained associated with other ethnic populations or if these associations were unique to these populations.

A recent study has identified a protective variant by conducting a GWAS on 5,570 cases and 6,279 controls [125]. The rare protective variant p.Tyr407Phe in LOXL1 was only identified in the Japanese population, though populations from the United States, Greece, Italy, India, Pakistan, South Africa, Mexico, and Russia. To underscore the rareness of the variant, of the 3,909 Japanese cases with PXF syndrome, only 2 samples were found to have the rs201011613-T (LOXL1 p.Tyr407Phe) compared to 68 in the 5,388 controls [125].

\section{Potential molecular mechanisms}

Transforming growth factor beta 1 (TGF- $\beta 1$ ) has been associated with a higher risk of PXF due to its role in the fibrotic process $[118,124,126]$. TGF- $\beta 1$ was found to be present in more significant amounts within the aqueous humor, anterior segment, and PXF deposits of eyes with PXF [118, 124]. As mentioned prior, LOXL1 is significantly associated with PXF, and TGF- $\beta 1$ has been found to increase expression of LOXL1 [118]. Homocysteine levels are also associated with PXF and PXG [127-129]. A cross-sectional study conducted in the US with 124 participants, including Whites, Hispanics, Asians, and Blacks, found that in patients with PXF and PXG, had significantly elevated blood plasma levels of homocysteine, which has been previously associated with cardiovascular disease [127]. Clusterin has also been associated with the risk of PXF [130]. Clusterin is a ubiquitous protein found throughout the body and a component of PXF exfoliation material and Clusterin protein levels are found to be higher in those with PXG $[118,131,132]$. TGF- $\beta 1$, homocysteine, and Clusterin could be potential biomarkers for PXF and/or PXG.

\section{PXF around the globe}

\section{Asia}

As the largest continent globally, the most populous, and with many different cultures and communities in every region, the prevalence of PXF varies across Asia [133, 134]. In Northern China, in one hospitalbased study of 8,205 cataract patients aged 60+ years old, PXF was found to be quite low and found in only $0.55 \%$ of study participants [135]. In Pakistan, the prevalence of PXF has been reported to be $6.45 \%$ of the population [136]. This was confirmed by a prospective study of 1,890 participants aged 45 to 87 years old that found that $40 \%$ of those with PXF had high IOP [136]. In Singapore, the prevalence of PXF was reported to be $2.8 \%$ [134] and confirmed by a retrospective study of 1,459 male and 1,858 female participants, aged $40+$ years old. The Singapore study also observed that those with PXF were more likely to be of Indian 
ethnicity than Chinese [134]. This variation by region reinforces the need to conduct further research across populations to understand the prevalence of the PXF and associated risks.

\section{Africa}

Several studies conducted in Africa have shown that the prevalence of PXF varies by geographic location [137-141]. A cross-sectional study of 2,142 Congolese patients, (57.5\% men) showed the prevalence of PXF was 1.7\% [137]. This was lower than the prevalence of PXF reported in a crossectional study of 1,840 participants in two separate districts in South Africa, Temba (6.0\%) and Hlabisa (7.7\%), in a cross-sectional study of [138]. The prevalence of PXF in the Congolese was more similar to the $2.7 \%$ prevalence of PXF found in Nigeria in a hospital-based study, including 448 participants aged 30-90 years old [139]. In Northern Nigeria, the prevalence of PXF was found to be 1.5\% [140]. There are fifty-four states in Africa with varying cultures, tribes, and social constructs [142], research within each population will be needed to truly understand PXF and the unique risk factors driving disease prevalence. Therefore, estimates at the continent level will have lesser utility in understanding the variation of PXF risk and etiology.

\section{Australia}

There have been several studies conducted in Australia to identify the prevalence of PXF $[143,144]$. The Visual Impairment Project study cohort consisted of three distinct populations, including 3,271 urban participants aged 40 to 98 years old, 1,473 nursing home participants aged 46 to 101 years old, and 1,473 rural participants aged 40 to 95 years old [143]. The sex breakdown was $46 \%, 21 \%$, and $48 \%$ men, respectively [143]. Prevalence of PXF was $0.98 \%$ in the overall population but $6.0 \%$ in those aged 80-89 [144]. This study found that PXF material increased with age and that those with glaucoma were more likely to also have PXF [143]. The Framingham Eye Study evaluated 1,906 Australians aged 52 to 85 years old, of which $56.8 \%$ were women [145]. In this population, the prevalence of PXF was $1.8 \%$, and women were more likely to have the PXE adjusting for age [145]. Additionally, the Blue Mountains Eye study conducted in Australia found that PXF was prevalent in $2.3 \%$ of 3,654 participants aged 40+ years old [146]. The study also found that PXF was associated with a history of angina or hypertension and with a combined history of angina, stroke, and acute myocardial infarction [146]. In the Blue Mountains Eye Study and the Framingham study, more women, had PXF, while in the Visual Impairment Project, more men had PXF. In all three studies, sex was not statistically associated with PXF. In the indigenous population of Central Australia, the prevalence of PXF was found to be $4.7 \%$ in a study of 1,884 participants aged $20+$ years old (36\% males) [147]. None of the participants in this population had glaucoma or ocular hypertension, but the study did find an association between PXF and climatic droplet keratopathy [147]. Prevalence in this population was higher than in the populations in the Visual Impairment Project, the Blue Mountain Eyes Study, and the Framingham Eye Study. It may be that the indigenous population in central Australia has a greater exposure to sunlight coupled with less access to prevention and treatment.

\section{Europe}

PXF prevalence has been well studied throughout regions in Europe [109, 148-150]. The highest PXF in Europe reported was among Icelanders, Finns, Russians, and Lapps residing in Novosibirsk, Russia of 21\% [149]. The lowest prevalence of PXF has been reported in the Greenland indigenous population at $0 \%$, in a population-based study of those were $60+$ years old which included multiple ethnicities [32,146]. Prevalence of PXF in other countries, including England, Germany, and Norway, ranged from about 4-6\% [32, 150]. In a cross-sectional study of 2,140 Greek patients with cataract (50.8\% men), the prevalence of PXF was found to be $27.9 \%$ [71]. It was also found within this study that the risk for PXF increased with age, and those with PXF experienced a higher rate of developing glaucoma [71].

\section{North America}

The prevalence of PXF can differ throughout North America's geography as the population is ethnically and racially diverse. In the Navajo American Indian population of Arizona, the prevalence of PXF was $38 \%[151,152]$, as seen in a hospital-based study which included 50 Navajo participants aged 60+ 
years old [151, 152]. A prospective study conducted in the Southeastern Region of the US found the prevalence to be $1.6 \%$ in 1,216 female and 905 male participants aged $60+$ years old [153]. A Southern Louisiana study of open-angle glaucoma patients aged $50+$ years old found the prevalence of PXF was $2.7 \%$ in Whites and $0.4 \%$ in black participants [154].

\section{South America}

PXF prevalence differs across South America [155-157]. In a study that included 159 participants aged 50+ years old in Peru, the prevalence of PXF was 4.4\% [156] and increased with age. Prevalence of PXF in Paraguay has been reported to be $17.1 \%$ in 268 female and 200 male patients aged 50+ years old with a diagnosis of senile cataract [157]. A lower prevalence was reported in a study of the population in Argentina. Among 337 participants (69.4\% male), 14.5\% had PXF, and again the prevalence increased with age [155]. Within Guatemala, there have been three studies documenting the prevalence of PXF. In the Guatemala Clinic National of oftalmología, the prevalence of PXF was to be $5 \%$ in 4,748 patients, (63.3\% women) [158]. A retrospective study of patients with cataract, found that $15 \%$ of 259 patients at Hospital de la Familia in Guatemala had PXF [159]. Lastly, a cross-sectional study of a Mayan cohort at Salama Lion's Eye Club Hospital found that $24.6 \%$ had PXF [160].

\section{Underserved populations and PXF}

Underserved populations are often understudied within scientific research, including research about eye disease such as PXF, leading to the persistence of health disparities within these populations [161-163]. By exclusion from research that advances the understanding of risk and treatment of many diseases, including blinding eye disease, understudied populations will benefit less from such advances and be disproportionally burdened by disease because individual population health and preventive care needs will be unknown [161-163]. It is important for research to include underserved populations within the research. It can also suggest unique or tailored paradigms for disease risk and prevention, especially if these populations are within rural areas or are isolated [164]. Isolated populations can help aid the understanding of PXF by providing greater genetic homogeneity as compared to other populations [164-166]. These populations also may be more homogenous in terms of cultural, environmental exposure, and societal norms, including diet, exercise, elevation from sea level, exposure to the sun, and climate change effects [164]. Isolated populations may increase the power to identify unique genetic and/or environmental associations with disease outcomes to be used in future studies with other populations [164,167, 168]. Moreover, it is ethical to include these underserved populations within research to address health disparities and to achieve global health equity. If research does not understand health disparities within the context of a wide range of diseases, newly emerging diseases, such as COVID-19, will disproportionally burden these populations on a greater scale [169-171].

\section{Conclusion}

There is a need for research to identify any clinical, environmental, demographic, and genetic risk factors that may differ by populations that may predispose individuals to develop PXF or secondary disease. Identifying genes that may be associated with PXF can also help identify individuals with a predisposition to developing pathology. Further research is needed in geographically isolated populations in which PXF has yet to be studied or understudied. This research may inform those that create policy and other individuals who are planning and providing relevant health care and preventative care services [157]. In each population, PXF needs may be different, and by having research that identifies individual population needs about PXF, the resources in that population can be more efficiently utilized. Otherwise, PXF intervention and care management based only on the broadest level of understanding may continue to create further health disparities in populations disproportionally burdened by PXF. Instead, specific populations' individual needs should be studied to create a tailored approach for preventative care and medical treatment [164]. If individualized approaches cannot be tailored to meet individual populations' needs, then health equity 
cannot be achieved, and health disparities will remain as these populations will not equally benefit from advancements in medicine [164].

\author{
Abbreviations \\ GWAS: genome-wide association study \\ IOP: intraocular pressure \\ PXF: pseudoexfoliation \\ PXG: pseudoexfoliation glaucoma \\ SNPs: single nucleotide polymorphisms \\ TGF- $\beta 1$ : transforming growth factor beta 1
}

\title{
Declarations
}

\section{Author contributions}

Concept and design: $\mathrm{PMH}, \mathrm{BH}, \mathrm{LAO}, \mathrm{EA}, \mathrm{MF}, \mathrm{MAM}$ and MMD; acquisition, analysis, or interpretation of data: PMH, AS, BH, LAO, EA, MF, MAM, SS, AR, JL, and MMD; drafting of the manuscript: PMH, AS, BH, LAO, EA, MAM, MF, SS, AR, JL, and MMD; critical revision: PMH, BH, LAO, MF, MAM, SS, AR, JL, and MMD; supervision: PMH, LAO, MF, MAM, and MMD.

\section{Conflicts of interest}

Dr. Hicks reported receiving funding support from the African American Doctoral Scholar Initiative at the University of Utah and the Emerging Diversity Scholars Fellowship at the University of Utah. Dr. DeAngelis reported receiving funding from the Ira G. Ross and Elizabeth Olmsted Ross Endowment at the University of New York at Buffalo. Dr. Owen reported receiving funding support from Research to Prevent Blindness and the National Institutes of Health. The other authors declare they have no conflicts of interest.

\section{Ethical approval}

Not applicable.

\section{Consent to participate}

Not applicable.

\section{Consent to publication}

Not applicable.

\section{Availability of data and materials}

Not applicable.

\section{Funding}

This research was funded by the National Eye Institute Grant [K08EY031800], National Institutes of Health Core Grant [EY014800], Unrestricted Grant from Research to Prevent Blindness, Inc., New York, NY, to the Department of Ophthalmology \& Visual Sciences, University of Utah, the Ira G. Ross and Elizabeth Olmsted Ross Endowment at the University of New York at Buffalo, the Emerging Diversity Scholars Fellowship at the University of Utah and the African American Doctoral Scholars Initiative at the University of Utah. This work was also supported, in part, by facilities and resources provided by the "VA Western NY Healthcare System." The opinions expressed herein are not those of the Department of Veterans Affairs or any other agency of the U.S. Government. The funding sources had no role in the design and conduct of the study; collection, management, analysis, and interpretation; preparation, review, or approval of the manuscript; and decision to submit the manuscript for publication. 


\section{Copyright}

(c) The Author(s) 2021.

\section{References}

1. Tran VT. UBM/slit-lamp-photo imaging of pseudoexfoliation deposits in the iridocorneal angle: imaging clues to the genesis of ocular hypertension. Int Ophthalmol. 2009;29:389-92.

2. Lindberg JG. Clinical investigations on depigmentation of the pupillary border and translucency of the iris in cases of senile cataract and in normal eyes in elderly persons. Acta Ophthalmol Suppl. 1989;190:1-96.

3. Stafiej J, Hałas-Wiśniewska M, Izdebska M, Gagat M, Grzanka D, Grzanka A, et al. Immunohistochemical analysis of microsomal glutathione S-transferase 1 and clusterin expression in lens epithelial cells of patients with pseudoexfoliation syndrome. Exp Ther Med. 2017;13:1057-63.

4. Patel AS, Stelzner SK. Pseudoexfoliation syndrome. EyeWiki [Internet]. [cited 2020 Jan 21]. Available from: https://eyewiki.aao.org/Pseudoexfoliation_Syndrome\#Disease

5. Elhawy E, Kamthan G, Dong CQ, Danias J. Pseudoexfoliation syndrome, a systemic disorder with ocular manifestations. Hum Genomics. 2012;6:22.

6. Majka CP, Challa P. Diagnosis and management of pseudoexfoliation glaucoma. EyeNet Magazine [Internet]. 2006 Jun [cited 2020 Jan 21]. Available from: https://www.aao.org/eyenet/article/diagnosismanagement-of-pseudoexfoliation-glaucoma

7. Angelilli A, Ritch R. Directed therapy for exfoliation syndrome. Open Ophthalmol J. 2009;3:70-4.

8. Sangal N, Chen TC. Cataract surgery in pseudoexfoliation syndrome. Semin Ophthalmol. 2014;29:403-8.

9. Amini H, Daneshvar R, Eslami Y, Moghimi S, Amini N. Early-onset pseudoexfoliation syndrome following multiple intraocular procedures. J Ophthalmic Vis Res. 2012;7:190-6.

10. Cumurcu T, Dorak F, Cumurcu BE, Erbay LG, Ozsoy E. Is there any relation between pseudoexfoliation syndrome and Alzheimer's type dementia? Semin Ophthalmol. 2013;28:224-9.

11. Brissette AR, Schweitzer K, Campbell RJ. Answer: can you identify this condition? Can Fam Physician. 2011;57:687-8.

12. Ritch R, Schlötzer-Schrehardt U. Exfoliation (pseudoexfoliation) syndrome: toward a new understanding: proceedings of the First International Think Tank. Acta Ophthalmol Scand. 2001;79:213-7.

13. Browne JG, Ho SL, Kane R, Oliver N, Clark AF, O'Brien CJ, et al. Connective tissue growth factor is increased in pseudoexfoliation glaucoma. Invest Ophthalmol Vis Sci. 2011;52:3660-6.

14. Ariga M, Nivean M, Utkarsha P. Pseudoexfoliation syndrome. J Curr Glaucoma Pract. 2013;7:118-20.

15. Schlötzer-Schrehardt U, Naumann GO. Trabecular meshwork in pseudoexfoliation syndrome with and without open-angle glaucoma. A morphometric, ultrastructural study. Invest Ophthalmology Vis Sci. 1995;36:1750-64.

16. Rao A, Padhy D. Pattern of pseudoexfoliation deposits on the lens and their clinical correlation-clinical study and review of literature. PLoS One. 2014;9:e113329.

17. Vardhan SA, Haripriya A, Ratukondla B, Ramulu P, Shivakumar C, Nath M, et al. Association of pseudoexfoliation with systemic vascular diseases in a South Indian population. JAMA Ophthalmol. 2017;135:348-54.

18. Schlötzer-Schrehardt U, Naumann GO. Ocular and systemic pseudoexfoliation syndrome. Am J Ophthalmol. 2006;141:921-37.e2.

19. Zikou AK, Kitsos G, Astrakas LG, Xydis VG, Spiliopoulos K, Bagli E, et al. Pseudoexfoliation syndrome without glaucoma: white matter abnormalities detected by conventional MRI and diffusion tensor imaging. Eur J Radiol. 2018;99:82-7. 
20. Katsi V, Pavlidis AN, Kallistratos MS, Fitsios A, Bratsas A, Tousoulis D, et al. Cardiovascular repercussions of the pseudoexfoliation syndrome. N Am J Med Sci. 2013;5:454-9.

21. French DD, Margo CE, Harman LE. Ocular pseudoexfoliation and cardiovascular disease: a national cross-section comparison study. N Am J Med Sci. 2012;4:468-73.

22. Nazarali S, Damji F, Damji KF. What have we learned about exfoliation syndrome since its discovery by John Lindberg 100 years ago? Br J Ophthalmol. 2018;102:1342-50.

23. Aboobakar IF, Johnson WM, Stamer WD, Hauser MA, Allingham RR. Major review: exfoliation syndrome; advances in disease genetics, molecular biology, and epidemiology. Exp Eye Res. 2017;154:88-103.

24. Yildirim N, Yasar E, Gursoy H, Colak E. Prevalence of pseudoexfoliation syndrome and its association with ocular and systemic diseases in Eskisehir, Turkey. Int J Ophthalmol. 2017;10:128-34.

25. Challa P. Genetics of pseudoexfoliation syndrome. Curr Opin Ophthalmol. 2009;20:88-91.

26. Vahedian Z, Salmanroghani R, Fakhraie G, Moghimi S, Eslami Y, Zarei R, et al. Pseudoexfoliation syndrome: effect of phacoemulsification on intraocular pressure and its diurnal variation. J Curr Ophthalmol. 2015;27:12-5.

27. Porter D. Pseudoexfoliation syndrome. EyeSmart [Internet]. [cited 2021 Mar 9]. Available from: https:// www.aao.org/eye-health/diseases/what-is-pseudoexfoliation

28. Hammer T, Schlötzer-Schrehardt U, Naumann GO. Unilateral or asymmetric pseudoexfoliation syndrome? An ultrastructural study. Arch Ophthalmol. 2001;119:1023-31.

29. Kozart DM, Yanoff M. Intraocular pressure status in 100 consecutive patients with exfoliation syndrome. Ophthalmology. 1982;89:214-8.

30. Ritch R. Exfoliation syndrome-the most common identifiable cause of open-angle glaucoma. J Glaucoma. 1994;3:176-7.

31. Hirvelä $\mathrm{H}$, Luukinen $\mathrm{H}$, Laatikainen L. Prevalence and risk factors of lens opacities in the elderly in Finland. A population-based study. Ophthalmology. 1995;102:108-17.

32. Shazly TA, Farrag AN, Kamel A, Al-Hussaini AK. Prevalence of pseudoexfoliation syndrome and pseudoexfoliation glaucoma in Upper Egypt. BMC Ophthalmology. 2011;11:18.

33. Weinreb RN, Aung T, Medeiros FA. The pathophysiology and treatment of glaucoma: a review. JAMA. 2014;311:1901-11.

34. Kingman S. Glaucoma is second leading cause of blindness globally. Bull World Health Organ. 2004;82:887-8.

35. Glaucoma [Internet]. St. Louis: American Optometric Association; [cited 2020 Jan 22]. Available from: https://www.aoa.org/patients-and-public/eye-and-vision-problems/glossary-of-eye-and-visionconditions/glaucoma

36. Glaucoma [Internet]. Bethesda: National Eye Institute; [cited 2020 Jan 22]. Available from: https:// www.nei.nih.gov/learn-about-eye-health/eye-conditions-and-diseases/glaucoma

37. Glaucoma [Internet]. Mayo Clinic; c1998-2021 [cited 2020 Jan 22]. Available from: https://www. mayoclinic.org/diseases-conditions/glaucoma/symptoms-causes/syc-20372839

38. Boyd K. What is glaucoma? Symptoms, causes, diagnosis, treatment. EyeSmart [Internet]. 2020 Jan [cited 2020 Jan 22]. Available from: https://www.aao.org/eye-health/diseases/what-is-glaucoma

39. Ritch R, Schlötzer-Schrehardt U, Konstas AG. Why is glaucoma associated with exfoliation syndrome? Prog Retin Eye Res. 2003;22:253-75.

40. Angelilli A, Ritch R. Directed therapy: an approach to the improved treatment of exfoliation syndrome. Middle East Afr J Ophthalmol. 2009;16:35-40.

41. Aboobakar IF, Allingham RR. Genetics of exfoliation syndrome and glaucoma. Int Ophthalmol Clin. 2014;54:43-56.

42. Vesti E, Kivelä T. Exfoliation syndrome and exfoliation glaucoma. Prog Retin Eye Res. 2000;19:345-68. 
43. Ritch R. The management of exfoliative glaucoma. Prog Brain Res. 2008;173:211-24.

44. Bansal RK, Tsai JC. Compliance/adherence to glaucoma medications-a challenge. J Curr Glaucoma Pract. 2007;1:22-5.

45. Feehan M, Munger MA, Cooper DK, Hess KT, Durante R, Jones GJ, et al. Adherence to glaucoma medications over 12 months in two US Community Pharmacy chains. J Clin Med. 2016;5:79.

46. Don't let glaucoma steal your sight! [Internet]. Centers for Disease Control and Prevention; [cited 2020 Jan 22]. Available from: https://www.cdc.gov/visionhealth/resources/features/glaucoma-awareness.html

47. Jonasson F. From epidemiology to lysyl oxidase like one (LOXL1) polymorphisms discovery: phenotyping and genotyping exfoliation syndrome and exfoliation glaucoma in Iceland. Acta Ophthalmol. 2009;87:478-87.

48. Dewundara S, Pasquale LR. Exfoliation syndrome: a disease with an environmental component. Curr Opin Ophthalmol. 2015;26:78-81.

49. Blindness and vision impairment [Internet]. Geneva: World Health Organization; c2021 [cited 2021 Oct 14]. Available from: https://www.who.int/news-room/fact-sheets/detail/blindness-and-visualimpairment

50. Cataracts [Internet]. Bethesda: National Eye Institute; [cited 2020 Jan 22]. Available from: https://www. nei.nih.gov/learn-about-eye-health/eye-conditions-and-diseases/cataracts

51. Cataracts: 3 common types, causes, symptoms and treatments [Internet]. All About Vision; c2000-2021 [cited 2020 Jan 22]. Available from: https://www.allaboutvision.com/conditions/cataracts.htm

52. Boyd K. What are cataracts? EyeSmart [Internet]. [cited 2021 Jan 22]. Available from: https://www.aao. org/eye-health/diseases/what-are-cataracts

53. Cataracts [Internet]. Mayo Clinic; c1998-2021 [cited 2020 Jan 22]. Available from: https://www. mayoclinic.org/diseases-conditions/cataracts/symptoms-causes/syc-20353790

54. Types of cataract [Internet]. Bethesda: National Eye Institute; [cited 2020 Jan 22]. Available from: https://www.nei.nih.gov/learn-about-eye-health/eye-conditions-and-diseases/cataracts/types-cataract

55. Murthy G, John N, Shamanna BR, Pant HB. Elimination of avoidable blindness due to cataract: where do we prioritize and how should we monitor this decade? Indian J Ophthalmol. 2012;60:438-45.

56. Mathenge W, Nkurikiye J, Limburg H, Kuper H. Rapid assessment of avoidable blindness in Western Rwanda: blindness in a postconflict setting. PLoS Med. 2007;4:e217.

57. Dineen B, Bourne RR, Jadoon Z, Shah SP, Khan MA, Foster A, et al; Pakistan National Eye Survey Study Group. Causes of blindness and visual impairment in Pakistan. The Pakistan national blindness and visual impairment survey. Br J Ophthalmol. 2007;91:1005-10.

58. Limburg H, Barria von-Bischhoffshausen F, Gomez P, Silva JC, Foster A. Review of recent surveys on blindness and visual impairment in Latin America. Br J Ophthalmol. 2008;92:315-9.

59. Kanthan GL, Mitchell P, Burlutsky G, Rochtchina E, Wang JJ. Pseudoexfoliation syndrome and the long-term incidence of cataract and cataract surgery: the Blue Mountains Eye Study. Am J Ophthalmol. 2013;155:83-8.e1.

60. Ekström C, Botling Taube A. Pseudoexfoliation and cataract surgery: a population-based 30-year follow-up study. Acta Ophthalmol. 2015;93:774-7.

61. Fontana L, Coassin M, Iovieno A, Moramarco A, Cimino L. Cataract surgery in patients with pseudoex-foliation syndrome: current updates. Clin Ophthalmol. 2017;11:1377-83.

62. Arnarsson A, Sasaki H, Jonasson F. Twelve-year incidence of exfoliation syndrome in the Reykjavik eye study. Acta Ophthalmol. 2013;91:157-62.

63. Ritch R. Ocular findings in exfoliation syndrome. J Glaucoma. 2018;27:S67-71.

64. Öncel BA, Pinarci E, Akova YA. Tear osmolarity in unilateral pseudoexfoliation syndrome. Clin Exp Optom. 2012;95:506-9. 
65. Škegro I, Suić SP, Kordić R, Jandroković S, Petriček I, Kuzman T, et al. Ocular surface disease in pseudoexfoliation syndrome. Coll Antropol. 2015;39:43-5.

66. Konstas AG, Ritch R, Bufidis T, Morales J, Qi Y, Streeten BW. Exfoliation syndrome in a 17-year-old girl. Arch Ophthalmol. 1997;115:1063-7.

67. Hørven I, Hutchinson BT. Exfoliation syndrome: case reports of 31 and 35-year-old patients. Acta Ophthalmologica. 1967;45:294-8.

68. Vazquez-Ferreiro P, Carrera-Hueso FJ, Fikri-Benbrahim N, Barreiro-Rodriguez L, Diaz-Rey M, Ramón Barrios MA. Intraocular lens dislocation in pseudoexfoliation: a systematic review and meta-analysis. Acta Ophthalmol. 2017;95:e164-9.

69. Jehan FS, Mamalis N, Crandall AS. Spontaneous late dislocation of intraocular lens within the capsular bag in pseudoexfoliation patients. Ophthalmology. 2001;108:1727-31.

70. Eroglu FC, Sekeroglu MA, Ceran TH, Simsek M, Hondur G. Evaluation of lacrimal drainage system in pseudoexfoliation syndrome. Eye (Lond). 2021;[Epub ahead of print].

71. Andrikopoulos GK, Mela EK, Georgakopoulos CD, Papadopoulos GE, Damelou AN, Alexopoulos DK, et al. Pseudoexfoliation syndrome prevalence in Greek patients with cataract and its association to glaucoma and coronary artery disease. Eye (Lond). 2009;23:442-7.

72. Lamba PA, Giridhar A. Pseudoexfoliation syndrome. Indian J Ophthalmol. 1984;32:169-73.

73. Schlötzer-Schrehardt U. Pseudoexfoliation syndrome: the puzzle continues. J Ophthalmic Vis Res. 2012;7:187-9.

74. Kozobolis VP, Detorakis ET, Tsilimbaris MK, Vlachonikolis IG, Tsambarlakis IC, Pallikaris IG. Correlation between age-related macular degeneration and pseudoexfoliation syndrome in the population of Crete (Greece). Arch Ophthalmol. 1999;117:664-9.

75. Fact sheet: aging in the United States [Internet]. Washington: Population Reference Bureau; c2021 [cited 2020 Jan 22]. Available from: https://www.prb.org/aging-unitedstates-fact-sheet/

76. Ageing and health [Internet]. Geneva: World Health Organization; c2021 [cited 2020 Jan 22]. Available from: https://www.who.int/news-room/fact-sheets/detail/ageing-and-health

77. Select maps on the population 65 and older in the United States by county: 2013-2017 [Internet]. Washington: The United States Census Bureau; [cited 2020 Jan 22]. Available from: https://www.census. gov/library/visualizations/time-series/demo/nia_county_maps.html

78. Ageing [Internet]. New York: United Nations; [cited 2020 Jan 22]. Available from: https://www.un.org/ en/global-issues/ageing

79. World's older population grows dramatically [Internet]. Bethesda: National Institutes of Health; [cited 2020 Jan 22]. Available from: https://www.nih.gov/news-events/news-releases/worlds-olderpopulation-grows-dramatically

80. Menkin JA, Guan SA, Araiza D, Reyes CE, Trejo L, Choi SE, et al. Racial/ethnic differences in expectations regarding aging among older adults. Gerontologist. 2017;57:S138-48.

81. Regitz-Zagrosek, V. Sex and gender differences in health. Science \& Society Series on Sex and Science. EMBO Rep. 2012;13:596-603.

82. Women have a higher risk of stroke [Internet]. Dallas: American Stroke Association; c2021 [cited 2020 Jan 22]. Available from: https://www.stroke.org/en/about-stroke/stroke-risk-factors/women-have-ahigher-risk-of-stroke

83. What health issues or conditions affect women differently than men? [Internet]. Rockville: Eunice Kennedy Shriver National Institute of Child Health and Human Development; [cited 2020 Jan 22]. Available from: https://www.nichd.nih.gov/health/topics/womenshealth/ conditioninfo/howconditionsaffect 
84. Life expectancy for women [Internet]. Geneva: World Health Organization; c2021 [cited 2020 Jan 22]. Available from: https://www.who.int/data/gho/data/themes/topics/indicator-groups/indicatorgroup-details/GHO/life-expectancy-for-women

85. Ginter E, Simko V. Women live longer than men. Bratisl Lek Listy. 2013;114:45-9.

86. Zarulli V, Barthold Jones JA, Oksuzyan A, Lindahl-Jacobsen R, Christensen K, Vaupel JW. Women live longer than men even during severe famines and epidemics. Proc Natl Acad Sci U S A. 2018;115:E832-40.

87. ACOG Committee Opinion No. 586: Health disparities in rural women. Obstet Gynecol. 2014;123:384-8.

88. Legato MJ, Johnson PA, Manson JE. Consideration of sex differences in medicine to improve health care and patient outcomes. JAMA. 2016;3160:1865-6.

89. Hicks PM, Owen LA, DeAngelis MM. Global women's eye health: a genetic epidemiologic perspective. In: Prakash G, Iwata T, editiors. Advances in vision research, volume III: genetic eye research around the globe. Singapore: Springer Singapore; 2021. pp. 11-46.

90. Addressing sex differences in health [Internet]. Washington: Office on Women's Health; [cited 2020 Jan 22]. Available from: https://www.womenshealth.gov/30-achievements/27

91. Institute of Medicine (US) Forum on Neuroscience and Nervous System Disorders. Studying sex differences in health and disease. In: Sex differences and implications for translational neuroscience research: workshop summary. Washington (DC): National Academies Press (US); 2011. pp. 5-20.

92. Stein JD, Pasquale LR, Talwar N, Kim DS, Reed DM, Nan B, et al. Geographic and climatic factors associated with exfoliation syndrome. Arch Ophthalmol. 2011;129:1053-60.

93. Pasquale LR, Jiwani AZ, Zehavi-Dorin T, Majd A, Rhee DJ, Chen T, et al. Solar exposure and residential geographic history in relation to exfoliation syndrome in the United States and Israel. JAMA Ophthalmol. 2014;132:1439-45.

94. Kang JH, Wiggs JL, Pasquale LR. Relation between time spent outdoors and exfoliation glaucoma or exfoliation glaucoma suspect. Am J Ophthalmol. 2014;158:605-14.e1.

95. Thomas R, Nirmalan PK, Krishnaiah S. Pseudoexfoliation in southern India: the Andhra Pradesh eye disease study. Invest Ophthalmol Vis Sci. 2005;46:1170-6.

96. Rao A, Padhy D, Ramyashri S. Diet patterns and environmental correlates to disease in pseudo exfoliation syndrome. International J Curr Adv Res. 2019;8:17036-41.

97. Pasquale LR, Wiggs JL, Willett WC, Kang JH. The relationship between caffeine and coffee consumption and exfoliation glaucoma or glaucoma suspect: a prospective study in two cohorts. Invest Ophthalmol Vis Sci. 2012;53:6427-33.

98. Kang JH, Loomis SJ, Wiggs JL, Willett WC, Pasquale LR. A prospective study of folate, vitamin B6, and vitamin B12 intake in relation to exfoliation glaucoma or suspected exfoliation glaucoma. JAMA Ophthalmol. 2014;132:549-59.

99. Pasutto F, Zenkel M, Hoja U, Berner D, Uebe S, Ferrazzi F, et al. Pseudoexfoliation syndrome-associated genetic variants affect transcription factor binding and alternative splicing of LOXL1. Nat Commun. 2017;8:15466.

100. Chen L, Jia L, Wang N, Tang G, Zhang C, Fan S, et al. Evaluation of LOXL1 polymorphisms in exfoliation syndrome in a Chinese population. Mol Vis. 2009;15:2349-57.

101. Mayinu, Chen X. Evaluation of LOXL1 polymorphisms in exfoliation syndrome in the Uygur population. Mol Vis. 2011;17:1734-44.

102. Lemmelä S, Forsman E, Onkamo P, Nurmi H, Laivuori H, Kivelä T, et al. Association of LOXL1 gene with Finnish exfoliation syndrome patients. J Hum Genet. 2009;54:289-97. 
103. Álvarez L, García M, González-Iglesias H, Escribano J, Rodríguez-Calvo PP, Fernández-Vega L, et al. LOXL1 gene variants and their association with pseudoexfoliation glaucoma (XFG) in Spanish patients. BMC Med Genet. 2015;16:72.

104. Whigham BT, Allingham RR. Review: the role of LOXL1 in exfoliation syndrome/glaucoma. Saudi J Ophthalmol. 2011;25:347-52.

105. Mossböck G, Renner W, Faschinger C, Schmut O, Wedrich A, Weger M. Lysyl oxidase-like protein 1 (LOXL1) gene polymorphisms and exfoliation glaucoma in a Central European population. Mol Vis. 2008;14:857-61.

106. Challa P, Schmidt S, Liu Y, Qin X, Vann RR, Gonzalez P, et al. Analysis of LOXL1 polymorphisms in a United States population with pseudoexfoliation glaucoma. Mol Vis. 2008;14:146-9.

107. Fingert JH, Alward WL, Kwon YH, Wang K, Streb LM, Sheffield VC, et al. LOXL1 mutations are associated with exfoliation syndrome in patients from the midwestern United States. Am J Ophthalmol. 2007;144:974-5.e1.

108. Yang X, Zabriskie NA, Hau VS, Chen H, Tong Z, Gibbs D, et al. Genetic association of LOXL1 gene variants and exfoliation glaucoma in a Utah cohort. Cell Cycle. 2008;7:521-4.

109. Jaimes M, Rivera-Parra D, Miranda-Duarte A, Valdés G, Zenteno JC. Prevalence of high-risk alleles in the LOXL1 gene and its association with pseudoexfoliation syndrome and exfoliation glaucoma in a Latin American population. Ophthalmic Genet. 2012;33:12-7.

110. Ye H, Jiang Y, Jing Q Li D, Maimaiti T, Kasimu D, et al. LOXL1 hypermethylation in pseudoexfoliation syndrome in the Uighur population. Invest Ophthalmol Vis Sci. 2015;56:5838-43.

111. Hayashi H, Gotoh N, Ueda Y, Nakanishi H, Yoshimura N. Lysyl oxidase-like 1 polymorphisms and exfoliation syndrome in the Japanese population. Am J Ophthalmol. 2008;145:582-5.e2.

112. Kasım B, İrkeç M, Alikaşifoğlu M, Orhan M, Mocan MC, Aktaş D. Association of LOXL1 gene polymorphisms with exfoliation syndrome/glaucoma and primary open angle glaucoma in a Turkish population. Mol Vis. 2013;19:114-20.

113. Rautenbach RM, Bardien S, Harvey J, Ziskind A. An investigation into LOXL1 variants in black South African individuals with exfoliation syndrome. Arch Ophthalmol. 2011;129:206-10.

114. Williams SE, Whigham BT, Liu Y, Carmichael TR, Qin X, Schmidt S, et al. Major LOXL1 risk allele is reversed in exfoliation glaucoma in a black South African population. Mol Vis. 2010;16:705-12.

115. Hewitt AW, Sharma S, Burdon KP, Wang JJ, Baird PN, Dimasi DP, et al. Ancestral LOXL1 variants are associated with pseudoexfoliation in Caucasian Australians but with markedly lower penetrance than in Nordic people. Hum Mol Genet. 2008;17:710-6.

116. Pandav SS, Chakma P, Khera A, Chugh N, Gupta PC, Thattaruthody F, et al. Lack of association between lysyl oxidase-like 1 polymorphism in pseudoexfoliation syndrome and pseudoexfoliation glaucoma in North Indian population. Eur J Ophthalmol. 2019;29:431-6.

117. Takitani GEDS, Azevedo AGB, Motta FL, Teixeira SH, Sallum JMF, Vessani RM. Exfoliation syndrome associated with LOXL1 gene polymorphisms in a Black patient from Latin America: a case report. Arq Bras Oftalmol. 2018;81:437-9.

118. Schlötzer-Schrehardt U. Molecular biology of exfoliation syndrome. J Glaucoma. 2018;27:S32-7.

119. Aung T, Ozaki M, Mizoguchi T, Allingham RR, Li Z, Haripriya A, et al; Blue Mountains Eye Study GWAS Team; Wellcome Trust Case Control Consortium 2; Crowston JG, Coote M, Zhao B, Sang J, Zhang N, You Q et al. A common variant mapping to CACNA1A is associated with susceptibility to exfoliation syndrome. Nat Genet. 2015;47:387-92.

120. Aung T, Chan AS, Khor CC. Genetics of exfoliation syndrome. J Glaucoma. 2018;27:S12-4.

121. Sakurada Y, Mabuchi F. Genetic risk factors for glaucoma and exfoliation syndrome identified by genome-wide association studies. Curr Neuropharmacol. 2018;16:933-41. 
122. Ma YN, Xie TY, Chen XY. Multiple gene polymorphisms associated with exfoliation syndrome in the Uygur population. J Ophthalmol. 2019;2019:9687823.

123. Nakano M, Ikeda Y, Tokuda Y, Fuwa M, Ueno M, Imai K, et al. Novel common variants and susceptible haplotype for exfoliation glaucoma specific to Asian population. Sci Rep. 2014;4:5340.

124. Schlötzer-Schrehardt U, Zenkel M, Küchle M, Sakai LY, Naumann GO. Role of transforming growth factor- $\beta 1$ and its latent form binding protein in pseudoexfoliation syndrome. Exp Eye Res. 2001;73:765-80.

125. Aung T, Ozaki M, Lee MC, Schlötzer-Schrehardt U, Thorleifsson G, Mizoguchi T, et al. Genetic association study of exfoliation syndrome identifies a protective rare variant at LOXL1 and five new susceptibility loci. Nat Genet. 2017;49:993-1004.

126. Liravi P, Zenkel M, Kruse FE, Schlötzer-Schrehardt U. The pathophysiology of pseudoexfoliation syndrome is affected by interaction of TGF- $\beta 1$ and LOXL 1. Acta Ophthalmol. 2015;93:ABS15-0554.

127. Bleich S, Roedl J, Von Ahsen N, Schlötzer-Schrehardt U, Reulbach U, Beck G, et al. Elevated homocysteine levels in aqueous humor of patients with pseudoexfoliation glaucoma. Am J Ophthalmol. 2004;138:162-4.

128. Vessani RM, Ritch R, Liebmann JM, Jofe M. Plasma homocysteine is elevated in patients with exfoliation syndrome. Am J Ophthalmol. 2003;136:41-6.

129. Roedl JB, Bleich S, Reulbach U, Rejdak R, Kornhuber J, Kruse FE, et al. Homocysteine in tear fluid of patients with pseudoexfoliation glaucoma. J Glaucoma. 2007;16:234-9.

130. Wiggs JL, Kang JH, Fan B, Levkovitch-Verbin H, Pasquale LR. A role for clusterin in exfoliation syndrome and exfoliation glaucoma? J Glaucoma. 2018;27:S61-6.

131. Padhy B, Nanda GG, Chowdhury M, Padhi D, Rao A, Alone DP. Role of an extracellular chaperone, clusterin in the pathogenesis of pseudoexfoliation syndrome and pseudoexfoliation glaucoma. Exp Eye Res. 2014;127:69-76.

132. Zenkel M, Kruse FE, Jünemann AG, Naumann GO, Schlötzer-Schrehardt U. Clusterin deficiency in eyes with pseudoexfoliation syndrome may be implicated in the aggregation and deposition of pseudoexfoliative material. Invest Ophthalmol Vis Sci. 2006;47:1982-90.

133. Countries in Asia [Internet]. Worldometer; [cited 2020 Jan 24]. Available from: https://www. worldometers.info/geography/how-many-countries-in-asia/

134. Lee JK, Wong EP, Ho SL. Pseudoexfoliation syndrome at a Singapore eye clinic. Clin Ophthalmol. 2015;9:1619-24.

135. Ren R, Ding J, Wang N, Teng CC, de Moraes GV, Jonas JB, et al. Clinical signs and characteristics of exfoliation syndrome and exfoliative glaucoma in Northern China. Asia Pac J Ophthalmol (Phila). 2015;4:86-8.

136. Rao RQ, Arain TM, Ahad MA. The prevalence of pseudoexfoliation syndrome in Pakistan. Hospital based study. BMC Ophthalmol. 2006;6:27.

137. Kaimbo Wa Kaimbo D. Pseudoexfoliation syndrome in Congolese patients. J Fr Ophtalmol. 2012;35:40-5.

138. Rotchford AP, Kirwan JF, Johnson GJ, Roux P. Exfoliation syndrome in black South Africans. Arch Ophthalmol. 2003;121:863-70.

139. Olawoye 00, Ashaye AO, Teng CC, Liebmann JM, Ritch R, Ajayi BG. Exfoliation syndrome in Nigeria. Middle East Afr J Ophthalmol. 2012;19:402-5.

140. Idakwo U, Olawoye O, Ajayi BG, Ritch R. Exfoliation syndrome in Northern Nigeria. Clin Ophthalmol. 2018;12:271-7.

141. Bartholomew RS. Pseudocapsular exfoliation in the Bantu of South Africa. II. Occurrence and prevalence. Br J Ophthalmol. 1973;57:41-5. 
142. How many African countries are members of the United Nations? [Internet]. New York: United Nations Dag Hammarskjöld Library; [cited 2020 Jan 24]. Available from: http://ask.un.org/faq/22882

143. Mccarty CA, Taylor HR. Pseudoexfoliation syndrome in Australian adults. Am J Ophthalmol. 2000;129:629-33.

144. Grarup N, Moltke I, Albrechtsen A, Hansen T. Diabetes in population isolates: lessons from Greenland. Rev Diabet Stud. 2015;12:320-9.

145. Hiller R, Sperduto RD, Krueger DE. Pseudoexfoliation, intraocular pressure, and senile lens changes in a population-based survey. Arch Ophthalmol. 1982;100:1080-2.

146. Mitchell P, Wang JJ, Hourihan F. The relationship between glaucoma and pseudoexfoliation: the Blue Mountains Eye Study. Arch Ophthalmol. 1999;117:1319-24.

147. Landers J, Henderson T, Craig J. Prevalence of pseudoexfoliation syndrome in indigenous Australians within central Australia: the Central Australian Ocular Health Study. Clin Exp Ophthalmol. 2012;40:454-7.

148. Kaljurand K, Teesalu P. Prevalence of exfoliation syndrome in Estonia. Eur J Ophthalmol. 2010;20:1012-7.

149. Forsius H. Prevalence of pseudoexfoliation of the lens in Finns, Lapps, Icelanders, Eskimos, and Russians. Trans Ophthalmol Soc U K. 1979;99:296-8.

150. Aasved H. Prevalence of fibrillopathia epitheliocapsularis (pseudoexfoliation) and capsular glaucoma. Trans Ophthalmol Soc U K. 1979;99:293-5.

151. Jiwani AZ, Pasquale LR. Exfoliation syndrome and solar exposure: new epidemiological insights into the pathophysiology of the disease. Int Ophthalmol Clin. 2015;55:13-22.

152. Faulkner HW. Pseudo-exfoliation of the lens among the Navajo Indians. Am J Ophthalmol. 1971;72:206-7.

153. Cashwell LF Jr, Shields MB. Exfoliation syndrome prevalence in a Southeastern United States population. Arch Ophthalmol. 1988;106:335-6.

154. Ball SF. Exfoliation syndrome prevalence in the glaucoma population of South Louisiana. Acta Ophthalmol Suppl. 1988;184:93-8.

155. Lerner S, Picotti C, Scaricaciottoli D, Basualdo S. Prevalence of exfoliation syndrome and exfoliative glaucoma in Buenos Aires, Argentina. Invest Ophthalmol Vis Sci. 2007;48:4338.

156. Forsius H. Exfoliation syndrome in various ethnic populations. Acta Ophthalmol Suppl. 1988;184:71-85.

157. Quiroga L, Lansingh VC, Samudio M, Peña FY, Carter MJ. Characteristics of the corneal endothelium and pseudoexfoliation syndrome in patients with senile cataract. Clin Exp Ophthalmol. 2010;38:449-55.

158. Spinel Peñuela JE, Alonzo MP. Sindrome de pseudoexfoliación en la clínica de glaucoma de la unidad nacional de oftalmología. Ciudad de Guatemala. Estudio transversal. Rev SCO. 2018;51:37-45.

159. Barger JL, Tsui E, Chen KC, Haberman I, Lee J, Park L. Epidemiology of pseudoexfoliation syndrome in a Guatemalan population-2-year follow-up. Invest Ophthalmol Vis Sci. 2017;58:781.

160. Hicks PM, Au E, Self W, Haaland B, Feehan M, Owen LA, et al. Pseudoexfoliation and cataract syndrome associated with genetic and epidemiological factors in a Mayan cohort of guatemala. Int J Environ Res Public Health. 2021;18:7231.

161. Wasserman J, Palmer RC, Gomez MM, Berzon R, Ibrahim SA, Ayanian JZ. Advancing health services research to eliminate health care disparities. Am J Public Health. 2019;109:S64-9.

162. Jackson L, Kuhlman C, Jackson F, Fox PK. Including vulnerable populations in the assessment of data from vulnerable populations. Front Big Data. 2019;2:19.

163. Pfeffer R. Hidden but not forgotten: the importance of including understudied populations in research. J Fam Strength. 2015;15. 
164. Hicks PM, Melendez SAC, Vitale A, Self W, Hartnett ME, Bernstein P, et al. Genetic epidemiologic analysis of hypertensive retinopathy in an underrepresented and rare federally recognized native American population of the intermountain west. J Community Med Public Health. 2019;3:152.

165. Andersen MK, Pedersen CE, Moltke I, Hansen T, Albrechtsen A, Grarup N. Genetics of type 2 diabetes: the power of isolated populations. Curr Diab Rep. 2016;16:65.

166. Nair AK, Baier LJ. Complex genetics of type 2 diabetes and effect size: what have we learned from isolated populations? Rev Diabet Stud. 2015;12:299-319.

167. Kristiansson K, Naukkarinen J, Peltonen L. Isolated populations and complex disease gene identification. Genome Biol. 2008;9:109.

168. Rudan I. Health effects of human population isolation and admixture. Croat Med J. 2006;47:526-31.

169. Webb Hooper M, Nápoles AM, Pérez-Stable EJ. COVID-19 and racial/ethnic disparities. JAMA. 2020;323:2466-7.

170. Dorn AV, Cooney RE, Sabin ML. COVID-19 exacerbating inequalities in the US. Lancet. 2020;395:1243-4.

171. Millett GA, Jones AT, Benkeser D, Baral S, Mercer L, Beyrer C, et al. Assessing differential impacts of COVID-19 on black communities. Ann Epidemiol. 2020;47:37-44. 